\title{
ICE AT MELTING POINT SLIDING OVER A PEBBLE SLAB-
} A FILM

\author{
By W. F. Budd and N. A. Blundy \\ (Antarctic Division, Department of Science, 568 St Kilda Road, Melbourne, Victoria 3004, \\ Australia)
}

Abstract. A time-lapse movie technique has been developed to study processes taking place near the interface when ice under high normal stress slides over a rough slab for shear stresses and sliding velocities comparable to those of real glaciers.

The "sledge rig" described by Budd and others (1979) was set up with one of the strips of ice ( $160 \mathrm{~mm}$ long and $23 \mathrm{~mm}$ wide) close to the edge of the pebble slab on which it rested. The normal stress was applied by loading the rig with lead to 5 bars. The shear stress was applied by a direct load on a cable over a pulley while the rig rested on the slab on a strong table. Shear stresses in the range $I$ to 2 bars were used giving velocities from about 50 to $500 \mathrm{~m} \mathrm{a}^{-1}$. Beyond 2 bars it was found that acceleration would set in, so this was avoided.

A time-lapse movie camera was set up beside the rig to focus first on the whole configuration and then on the ice and interface as a close-up. A flash light was set up behind the rig to shine through the ice strip. A scale rule was placed along the slab under the ice strip. A dial-gauge micrometer was also used to monitor displacement.

A time-lapse frequency of about $\mathrm{I}$ frame per $8 \mathrm{~s}$ was found to give a suitable speed. An automatic control triggered the camera and flash and also recorded the number of frames. A number of different markings were tried on the ice to indicate the relative ice deformation. Small graphite particle tracers were found the most successful.

A number of runs have been filmed showing the ice sliding speed increasing with increasing shear stress. The tests were carried out in a cold room at a temperature close to $0^{\circ} \mathrm{C}$.

Copies of the film can be made available at cost.

The authors were greatly assisted by Mr David Gardner of the Department of Educational Technology of Melbourne University by the provision of the filming equipment and general support for the operation.

\section{REFERENGE}

Budd, W. F., and others. 1979. Empirical studies of ice sliding, by W. F. Budd, P. L. Keage, and N. A. Blundy. Journal of Glaciology, Vol. 23, No. 89, p. $157-70$. 